\title{
Positive Illusions, Perceived Control and the Free Will Debate
}

\author{
THOMAS NADELHOFFER AND TATYANA MATVEEVA
}

\begin{abstract}
It is a common assumption among both philosophers and psychologists that having accurate beliefs about ourselves and the world around us is always the epistemic gold standard. However, there is gathering data from social psychology that suggest that illusions are quite prevalent in our everyday thinking and that some of these illusions may even be conducive to our overall well being. In this paper, we explore the relevance of these so-called 'positive illusions' to the free will debate. More specifically, we use the literature on positive illusions as a springboard for examining Saul Smilansky's so-called 'free will illusionism'. At the end of the day, we will use data from both social and developmental psychology concerning perceived control to try to show that his view is on shaky empirical footing.
\end{abstract}

\section{Introduction}

It is a common assumption among both philosophers and psychologists that having accurate beliefs about ourselves and the world around us is always the epistemic gold standard. However, there is gathering data from social psychology that suggest that illusions are quite prevalent in our everyday thinking and that some of these illusions may even be conducive to our overall well-being. In this paper, we are going to explore the relevance of these so-called 'positive illusions' to the free will debate. More specifically, we are going to use the literature on positive illusions as a springboard for examining Saul Smilansky's suggestion that (a) our purportedly commonplace beliefs in libertarian free will (LFW) and desert-entailing ultimate moral responsibility (UMR) are two such positive illusions, and (b) if people were to become disillusioned with respect to LFW and UMR, there would be wide-reaching negative intrapersonal and interpersonal consequences.

For present purposes, we are going to evaluate Smilansky's view — which he has dubbed free will illusionism-by ferreting out the empirical assumptions he

We would like to thank (a) Susan Feldman, an audience at Florida State University, and two referees at Mind $\&$ Language for very helpful comments on earlier drafts of this paper, (b) Adam Feltz for helping track down some of the research on atheism and happiness, and (c) Dickinson College for providing us with a DANA Assistantship to work on this paper during the summer of 2007. Finally, we owe a special debt of gratitude to Saul Smilansky who patiently and generously participated in the comment thread about a draft of this paper on the Garden of Forking Paths blog.

Address for correspondence: Dickinson College, Department of Philosophy, Carlisle, PA 17013, USA.

Email: tnadelhoffer@gmail.com 
needs in order to get his view off the ground. ${ }^{1}$ But first, we will examine the aforementioned data on positive illusions - especially the illusion of control-in order to give ourselves an empirical frame of reference $(\$ 1)$. Then we will examine Smilansky's free will illusionism to see whether the aforementioned research on positive illusions could be used to help bolster his view (\$2). Having considered Smilansky's position in light of the literature on the illusion of control, we will then use data from both social and developmental psychology concerning perceived control to try to show that his view is on shaky empirical footing (\$3). While Smilansky's worries concerning what would happen if people lost faith in LFW and UMR are understandable, his view does not appear to be as well-supported as it would need to be in order to garner our acceptance. If we are right, then the burden of motivating free will illusionism has yet to be met $(\mathbb{S} 4)$. Once we have tried to show that Smilansky has a heavy argumentative burden to shoulder, we will consider how he might respond to our criticisms and show why these responses are ultimately inadequate $(\$ 5)$. At the end of the day, we will suggest that we ought not to follow Smilansky down the road to free will illusionism until we have evidence for thinking the worries it is based upon are empirically well-founded (\$6).

\section{Positive Illusions and the Free Will Debate}

On the surface, it seems obvious that having accurate beliefs about both the world and oneself is necessary for psychological well-being. Consequently, it is no surprise that the orthodox view in psychology has always been that being in contact with reality is one of the hallmarks of mental health. According to this traditional view - which for present purposes we are going to call the Correspondence Theory of Well-Being (CTWB) - the ability to accurately perceive the reality about both oneself and the world is fundamental to effective psychological functioning (Jourard and Landsman, 1980, p. 75). ${ }^{2}$ However, contrary to this admittedly intuitive view of mental health, there is mounting evidence which suggests that widespread illusions may play a markedly more positive role in our mental economy than psychologists have previously assumed.

Consider, for instance, the suggestion by Shelley Taylor and Jonathon Brown that 'a set of interrelated positive illusions - namely, unrealistically positive self-evaluations, exaggerated perceptions of control or mastery, and unrealistic optimism - can serve a wide variety of cognitive, affective, and social functions' (1988, p. 193). It appears that contrary to what we've been told by the proponents of CTWB - who have traditionally portrayed humans as 'naive scientists' constantly

1 For an earlier attempt to criticize Smilansky's view in light of some of the preliminary free will studies that have been run by experimental philosophers, see Nadelhoffer and Feltz, 2007.

2 See, also, Allport, 1943; Jahoda, 1958; and Vaillant, 1977 for similar defenses of CTWB. 
searching for the truth about themselves and the world around them — the mounting evidence paints a much less flattering picture of humanity whereby we are much more like 'charlatans' who are, 'trying to make the data come out in a manner most advantageous to our already-held theories' (Fiske and Taylor, 1984, p. 88). ${ }^{3}$

As a result, it is now widely acknowledged that illusions, biases, and other cognitive errors are much more common in human cognition than previously assumed. Rather than single-mindedly pursuing the truth at all costs, we often settle for whatever evidence allows us to think more highly about ourselves in relation to other people and the world around us. More surprising still is the fact that these epistemically problematic inferences, beliefs, and judgments appear to be adaptive in a wide variety of domains. As Taylor and Brown point out:

Evidence from social cognition research suggests that, contrary to much traditional, psychological wisdom, the mentally healthy person may not be fully cognizant of the day-to-day flotsam and jetsam of life. Rather, the mentally healthy person appears to have the enviable capacity to distort reality in a direction that enhances self-esteem, maintains beliefs in personal efficacy, and promotes an optimistic view of the future. These three illusions, as we have called them, appear to foster traditional criteria of mental health, including the ability to care about the self and others, the ability to be happy or contented, and the ability to engage in productive and creative work. (1988, p. 204).

And while illusions exist on a continuum - ranging from totally delusional and destructive to minor and comforting - in this paper we are solely going to limit our attention to the so-called 'positive illusions'. More specifically, we are going to focus on the aforementioned 'illusion of control' identified by Taylor and Brown (1988) since it is the most germane to our present purposes. ${ }^{4}$

Psychologists from a variety of fields - e.g. developmental psychology (White, 1959), learning theory (Bandura, 1977; DeCharms, 1968), and social psychology (Heider, 1958) - have long recognized the importance of the sense of personal control. However, it appears that 'beliefs in personal control are sometimes greater than can be justified' (Taylor and Brown, 1988, p. 196). For instance, studies have shown that it is not uncommon for people to have the illusion of control even in situations that are determined entirely by chance (Langer, 1975).$^{5}$ It appears that when people expect a particular outcome to occur and it does occur, they frequently overestimate the degree to which they were instrumental in bringing it about (Taylor and Brown, 1988, p. 196) even in situations where control is mostly (or even entirely) lacking. ${ }^{6}$

See, e.g. Fiske and Taylor, 1984; Greenwald, 1980; Nisbett and Ross, 1980; and Taylor, 1989.

See also: Abramson and Alloy, 1981; Golin et al., 1977; Greenberg et al., 1988.

5 See also: Alloy and Abramson, 1979; Horswill and McKenna, 1999; Langer and Roth, 1975; Spacapan and Thomson, 1991.

$6 \quad$ See e.g. Miller and Ross, 1975. 
Perhaps the most interesting feature of the literature on the illusion of control isn't that it appears to be so pervasive in healthy individuals but rather that the mildly and severely depressed seem less susceptible to it. ${ }^{7}$ Indeed, research on what Mischel (1973) calls 'depressive realism' suggests that depressed individuals provide more accurate estimations of their degree of personal control than do nondepressed individuals (Taylor and Brown, 1988, p. 196). ${ }^{8}$ There are two distinct and important issues worth highlighting at this point. First, according to proponents of depressive realism, depressed individuals are in an epistemically advantaged position over the non-depressed when it comes to judgments concerning how much control they have over their environment. Second, it has purportedly been shown that this epistemic advantage may sometimes be emotionally and socially maladaptive. ${ }^{9}$ In light of these findings, Taylor and Brown conclude-contrary to the proponents of CTWB - that 'the capacity to develop and maintain positive illusions may be thought of as a valuable human resource to be nurtured and promoted ... these illusions help make the world a warmer and more active and beneficial place in which to live' (1988, p. 205).

Needless to say, this is a controversial claim that has received its fair share of criticism. ${ }^{10}$ Luckily, we need not concern ourselves here with the problems associated with the literature on positive illusions, the illusion of control, and depressive realism given that our goal is merely to see whether this literature could, in principle, lend support to work being done in the free will debate by Smilansky. For present purposes, we are simply going to assume for the sake of argument that positive illusions exist and that they are often emotionally and socially adaptive. The question we now want to address is whether Smilansky is correct in assuming that our purportedly common place beliefs in LFW and UMR are examples of these kinds of adaptive illusions. We are ultimately going to argue that the vast literature on perceived control — which we will examine in the following section-gives us reason to think that disillusionment would not be as dire as Smilansky suggests. But before we examine some control constructs from social and developmental psychology we first need to provide an overview of Smilansky's own view.

7 See e.g. Abramson and Alloy, 1981; Golin et al., 1979.

8 It's worth pointing out that in a review of the extensive literature on depression (Ackerman and DeRubeis, 1991) suggest that while several studies support the theory of depressive realism, just as many studies provide evidence that is inconsistent with the view. For instance, according to proponents of cognitive theories of depression, depressed individuals systematically interpret the world in a negative manner that is not congruent with reality-see, e.g. Abramson et al., 1989; Bargh and Tota, 1988; Beck, 1967, 1976. For present purposes, we need not come down on either side of the debate between those who favor depressive realism and those who favor cognitive models of depressive distortion as trying to settle the debate between the two rival camps would take us too far afield.

9 See, e.g. Brown, 1986; Campell and Fairey, 1985; Kuiper, 1978; Kuiper and Derry, 1982; Lewinsohn et al., 1980.

10 See, e.g. Colvin and Block, 1994; Cummins and Nistico, 2002. 


\section{Smilansky's Free Will Illusionism ${ }^{11}$}

Smilansky's argument for free will illusionism typically begins with a discussion of what he takes to be our ordinary moral practices. On his view, "most people not only believe in actual possibilities and the ability to transcend circumstances, but have distinct and strong beliefs that libertarian free will is a condition for moral responsibility, which is in turn a condition for just reward and punishment' (Smilansky, 2000, p. 27). ${ }^{12}$ Smilansky calls the kind of control that is necessary for robust conceptions of moral blameworthiness and desert 'up to usness', and he suggests that in one very important respect nothing is ultimately up to us. Because he believes (a) that LFW requires that an agent's actions ultimately flow from who she is morally, and (b) that 'what a person is, morally, cannot ultimately be under her control' (Smilansky, 2001, p. 74), Smilansky concludes both that LFW is non-existent and that the notions of UMR which depend on its existence are therefore ungrounded.

On his view, there appear on the surface to be only two responses-namely, compatibilism and hard determinism. And while we are told that neither of these two responses to the non-existence of LFW and UMR is wholly adequate, Smilansky nevertheless feels that each contains an important grain of truth. First, he points out that compatibilists are surely correct to highlight both the importance and the possibility of people having 'local reflective control over their actions' (Smilansky, 2001, p. 77). According to Smilansky, acknowledging that we have compatibilist control, second order volitions, reasons responsiveness, and the like is necessary if we are to foster a 'community of responsibility' - i.e. a community whereby people's lives and actions are judged to be based largely on their choices (Smilansky, 2001, p. 78). As he says, 'even without libertarian free will, it is reasonable to desire that compatibilist distinctions concerning control affect the way one is treated, and to see this as a condition for civilized existence' (2001, p. 78).

Smilansky nevertheless thinks that compatibilism is inadequate when it is judged from what he calls the 'ultimate perspective' (2001, p. 77). On his view, 'we can make sense of the notion of autonomy or self-determination on the compatibilist level but, if there is no libertarian free will, no one can be ultimately in control, ultimately responsible, for this self and its determinations' (2001, p. 75). For instance, even though we may justify punishing someone on compatibilist grounds, Smilansky suggests that we are nevertheless punishing her for 'what is ultimately her luck, for what follows from who she is - ultimately beyond her control, a state which she had no real opportunity to alter, hence neither her responsibility nor her fault' (2001, p. 76).

11 Parts of this section originally appeared in Nadelhoffer and Feltz, 2007.

12 It is unclear whether the belief in LFW and UMR is as widespread as Smilansky suggests. Indeed, recent work in the growing field of experimental philosophy suggests that people may be more compatibilist than philosophers have traditionally assumed. See, e.g. Nahmias et al., 2005, 2006; and Nahmias, 2006. 
Given that Smilansky thinks that we are not ultimately responsible for our actions, it would seem natural for him to simply promulgate hard determinism - a move he resists. For even though he believes that hard determinists are ultimately correct that we don't have LFW and UMR, Smilansky nevertheless believes that they are too quick to reject or undervalue the importance of compatibilist control for our everyday moral practices — practices which do not require LFW and UMR. By his lights, if the belief in hard determinism were to become widespread, the aforementioned compatibilistically grounded community of responsibility would likely be torn asunder. Indeed, Smilansky forebodingly warns that, 'the difficulties caused by the absence of ultimate-level grounding are likely to be great, generating acute psychological discomfort for many people and threatening morality - if, that is, we do not have illusion at our disposal' (Smilansky, 2001, p. 87). ${ }^{13}$

In this essay, we are going to follow Nadelhoffer and Feltz (2007) in calling this The Disutility of Disillusionment Assumption (DDA) - which is essentially the prediction that if people were to internalize the perspective of the hard determinist, the moral fabric that holds us together would unravel. On this view, the compatibilistically grounded moral norms and values that are central to individual and societal well-being could not weather the storm that would result from wide-scale awareness of the ultimate perspective. If Smilansky were correct in assuming that (a) the majority of people falsely believe both that we have LFW and that LFW is necessary for moral responsibility, and (b) disabusing people of these false beliefs would produce deleterious social and personal consequences, we would indeed find ourselves in quite a predicament.

So what does Smilansky suggest we do? According to free will illusionism, because the benefits of wide-scale illusory beliefs about the existence of LFW and UMR far outweigh the costs associated with dispelling these beliefs, "people as a rule ought not to be fully aware of the ultimate inevitability of what they have done' (Smilansky, 2001, p. 85). Consequently, those of us who have already been disillusioned ought to keep the truth to ourselves. ${ }^{14}$ On the surface, Smilansky's view concerning the importance of our purportedly illusory beliefs concerning LFW and UMR appears to be supported by the data on positive illusions discussed in Section 1. After all, he is essentially suggesting that having illusory beliefs about free will and desert-entailing responsibility — much like having other positive illusory beliefs such as the illusion of control — may be a blessing in disguise. But is he right about this?

In answering this question, it will prove useful to first do a bit more unpacking of Smilansky's DDA - which can be construed in the following way:

13 In this respect, Smilansky's position is squarely opposed to the aforementioned Correspondence Theory of Well-Being (CTWB). For whereas Smilansky claims that certain illusions are necessary for effective functioning, the proponents of CTWB claim just the opposite.

14 It is worth pointing out that Smilansky does not advocate intentionally deceiving people-he merely suggests that we should leave the misinformed masses to their illusory devices. 
1. Most people are under the spell of a positive illusion with respect to the dual existence of LFW and UMR.

2. If people were disillusioned about LFW and UMR, then they would lose sight of the fact that there is an important grain of truth in compatibilism-namely, that human beings do have the kind of local control that is necessary for grounding most of our moral practices as well as our sense of well-being.

3. Because disillusionment would produce negative emotional and social consequences, those of us who are aware that the beliefs in LFW and UMR are merely positive illusions should keep this fact to ourselves lest we lead people to throw out the compatibilist baby with the cold water of hard determinism.

Analyzing either the first or third premise would take us too far afield. ${ }^{15}$ By our lights, the key assumption is the second premise-i.e. the claim that being disillusioned about LFW and UMR would undermine people's sense of compatibilist control and moral responsibility. What we really want to ascertain is whether the inference from disillusionment to disutility is justified.

In order to properly evaluate Smilansky's argument, we are going to look more carefully at the literature on perceived control. After all, his attempt to motivate free will illusionism is driven by DDA - which is in turn driven by the assumption that accepting the truth of hard determinism would undermine our sense of control, autonomy, and responsibility. Fortunately, there is a voluminous literature in psychology concerning control that we can draw upon in trying to ascertain whether Smilansky's worries are well-founded. As we are about to see, the data from both social and developmental psychology suggest that they are not.

\section{Perceived Control and Experiential Control: Lessons from Old Age}

To say that the issue of personal control has received a lot of attention in the psychology literature would be a gross understatement. Given that individual differences in perceived control are related to a variety of positive outcomes, including health, achievement, optimism, persistence, motivation, coping, selfesteem, personal adjustment, and success and failure in a variety of life domains' (Skinner, 1996, p. 549), the attention psychologists have given to control is understandable. As a result, dozens of closely related control constructs have been

15 On the one hand, assessing the truth of the first premise would force us to wade into the thorny and often technical free will debate concerning the nature of LFW and UMR. On the other hand, the third premise depends on the truth of the second premise- which is the main target of our investigation. 
used by psychologists. ${ }^{16}$ That being said, only two aspects of personal control are particularly salient to the task at hand-namely, objective control and perceived control.

Objective control simply refers to how much actual control a person has over her decisions, actions, and environment. For an agent to have objective control over $x$ is for her to have the ability to do or not do $x$ as she sees fit. Typically, the kinds of things that limit our objective control include internal compulsions and external constraints and coercions. An individual who does not have objective control is not necessarily unfree in the strong metaphysical sense that concerns some philosophers but rather in the garden variety sense of unfree that we speak of when other people (or the world at large) prevent us from doing as we please. ${ }^{17}$ Consequently, it is understandable why we would prefer having objective control whenever possible. After all, to lack it is to be limited in one's opportunities and choices. But as important as we may believe having objective control is, it turns out to be less important than the second aforementioned aspect of control-i.e. perceived control.

Research has shown that perceived control — which refers to an individual's beliefs about how much control she has - is 'a more powerful predictor of functioning than actual control' (Skinner, 1996, p. 551). ${ }^{18}$ One explanation for why perceived control is so important to our overall well-being is that humans appear to have an innate desire to effectively engage with their environment. On this view, the desire for control is an essential component of human motivation. Indeed, as each of us learns early on in life, 'the experience of control is joyful, the loss of control can be devastating' (Skinner, 1995, p. xvii). And while this innate desire has been labeled differently by different researchers - e.g. effective motivation (White, 1959), mastery motivation (Harter, 1978), and the need for competence (Deci and Ryan, 1985) - the underlying idea is the same in each case. ${ }^{19}$

Because we have a desire for competence, causal efficacy, and control, we quite naturally do better when we believe that we have these things regardless of whether we actually do. In light of the importance of perceived control, researchers have investigated the link between our perceptions of control and a wide variety of things including 'health, achievement, school performance and retention, motivation, interpersonal competence, political beliefs, social action, parenting, teaching, marital satisfaction, work success, conformity, creativity, problem-solving, information seeking and processing, emotion, and longevity' (Skinner, 1995, p. 3). Moreover, clinical work has linked perceived control to 'coping, depression, anxiety, alienation, apathy, phobias, self-esteem, and

16 For overviews of the vast control and competency literature, see Haidt and Rodin, 1999; and Skinner, 1996.

17 In many respects, objective control is just the kind of control that the so-called soft determinists were interested in during the middle of the $20^{\text {th }}$ century. See, e.g. Stace, 1953; and Ayer, 1954.

18 See, e.g. Averill, 1973; and Burger, 1989.

19 See, also, DeCharms, 1981; Deci, 1975; Skinner, 1995, 1996. 
personal adjustment to critical life events' (Skinner, 1995, p. 3). All of this research suggests that believing we have control is essential to emotional and social well-being.

Now that we have examined the various aspects of control in a bit more detail, we are finally in a position to assess Smilansky's argument for free will illusionism. Keep in mind that on his view if people were to become disillusioned about LFW and UMR, they would cease to believe that they have the compatibilist control they actually do have - thereby creating potentially disastrous consequences. To put Smilansky's point in the language of the control and competency literature, disillusionment about LFW and UMR would undercut people's perceived control. But is this assumption supported by the gathering psychological data? It does not appear that it is. After all, the only thing required for perceived control is that the agent believes that she 'is interacting with the environment while attempting to produce a desired result or prevent an undesired outcome' (Skinner, 1996, p. 551).

If this is correct, then the joint belief in LFW and UMR may not be a positive illusion after all. In order for the purportedly mistaken belief concerning the existence of LFW and UMR to be a positive illusion, those who become disillusioned about LFW and UMR should be worse off than they were before. Of course, on Smilansky's view, they would be worse off given that once they became aware of the truth about the ultimate perspective, they would lose their faith in the compatibilist control and moral accountability they really do have. But, by our lights, it is unclear how ceasing to believe in LFW and UMR would cause people to believe that they have any less local control over their decisions and actions. And if they don't have less perceived local control, we see no reason to think their moral practices would change.

By our lights, even if Smilansky were correct that from the ultimate perspective 'luck swallows everything' - to borrow a phrase from Galen Strawson (1998) - there is no reason to conclude that our conscious beliefs, desires, intentions, decisions, and choices are mere epiphenomena. But insofar as our belief that our mental states are causally efficacious remains intact, we see no reason for assuming that being disillusioned about LFW and UMR would undermine our sense of local control, autonomy, and self-determination-each of which merely requires that we have at least some say in how our lives unfold. The ultimate perspective may teach us a lesson or two about the ubiquitous role that luck plays in our lives, but it does not show that our conscious mental states are causally inert. Of course, it could turn out that our conscious mental states really are little more than epiphenomena, but neither determinism nor the ultimate perspective entails epiphenomenalism. ${ }^{20}$ Hence, neither would undermine our sense of local and reflective control.

Keep in mind that Smilansky concedes that we do in fact have compatibilist control, he just thinks that once we view ourselves from the ultimate perspective,

20 For an extended discussion of this issue, see Nahmias, 2006. 
we see that while people do have 'local reflective control over their actions' (2001, p. 77), how this control gets exercised is entirely a matter of dumb luck. As he says:

Many people would find it hard to think that the partial compatibilist truth matters, as in fact it ethically does, if they realized the sense in which both the compatibilistically free and the unfree were merely performing according to their mould ... only if we do not see people from the ultimate perspective can we live in a way which compatibilism affirms - blaming, selectively excusing, respecting, being grateful, and the like (Smilansky, 2001, pp. 89-90).

But as intuitive as this view may seem on the surface, it is unclear that the disillusionment that concerns Smilansky would have the negative effects that he predicts. To see why, it would be helpful to look at what developmental psychologists have to say about control and competency.

As Ellen Skinner-one of the leading experts on constructs of control in psychology — points out:

Old age brings with it the recognition that many of life's events are the result of happenstance, luck, chance, fate, or coincidence. Events that are severe, negative, and nonnormative, such as early widowhood, disability, and victimization, are labeled accidents and rarely seem to be the result of any discernible systematic influences amenable to human control. At this age, many of the attributes that before were the objects of pride, such as mental ability, physical prowess, beauty, and robust health, are now seen in their decline as ultimately uncontrollable, and as characteristics that although genetic, are distributed based on luck as well ... It is as if, when reflecting on their control as they age, people change from psychologists, to sociologists, to historians, to philosophers (1995, p. 118).

Furthermore, she goes on to suggest that:

In a very general sense, then, the development of control during childhood can be thought of as a progressive realization of the limitations of one's own competence. The infant's global undifferentiated sense of agency is shorn of the power of longings and wishes; bounded by the effects of other people, task, difficulty, and chance; and brought up short by comparison to others performances. In contrast, adulthood can be conceptualized as a time of increasing recognition of the boundaries of contingency: a realization of the limits of human control and the narrow range of outcomes that can potentially be influenced by human action. Adults come to know that society imposes strict constraints on the competencies and people who will be rewarded, that history changes contingencies even within our lifetime, that chance and fate have a hand in all of life's successes and failures, and that the really important 
outcomes, death of self and loved ones, are out of human control (1995, pp. 121-122).

We have quoted Skinner at such length because we believe her remarks make it clear why Smilansky's dire predictions are unlikely to be borne out. It turns out that the process of disillusionment is one that we all undergo as we march inevitably from the cradle to the grave. Part of the aging process involves an increasing awareness of the ultimate perspective that Smilansky claims will have such a corrosive effect on our lives. And yet, because our sense of control is 'remarkably tenacious' and our 'efficacious self is very resilient (Skinner, 1995, p. 5), our gradual realization that luck played a bigger role in our lives than we had previously assumed leaves our beliefs and feelings of control largely intact. It appears that dislodging our perceived control requires awareness of actual loss of objective control. The mostly theoretical realization that even though we are often able to exercise local control over our actions, luck nevertheless plays an important role in how our lives turn out does not appear to be enough to undermine our beliefs and feelings of control.

In some important respect, we are all determined - a word we use with a hint of irony - to come to terms with the realization that from the ultimate perspective nearly everything we do and everything that happens to us is a matter of luck. But rather than being something people ought to be shielded from as Smilansky suggests, this process of disillusionment is part of the human condition. More importantly, so long as our belief in the causal efficacy of our mental states survives our gradual realization that at some level luck reigns supreme, our innate desire for control will continue to be satisfied at least as far as the issue of the ultimate perspective is concerned. If this is correct, then Smilansky's worries-as reasonable as they may seem to be on the surface-appear to be less grounded than he has assumed.

\section{Taking Stock}

At this point, we have now evaluated Smilansky's free will illusionism in light of the evidence from social and development psychology concerning positive illusions and perceived control. In short, we argued that while the literature on positive illusions appears on the surface to bolster Smilansky's inference from disillusionment to disutility, the evidence from the control and competency literature suggests that this move is unwarranted. It appears that in order for disillusionment about LFW and UMR to have the negative emotional and social effects that Smilansky envisions it would need to lead people to believe that their mental states are mere epiphenomena. But given that Smilansky himself suggests that we do have local control even if we don't have ultimate control, it seems that he is committed to the falsity of epiphenomenalism no less than the non-philosophers he is trying to shield 
from the purported truth about the ultimate perspective. ${ }^{21}$ So, either Smilansky needs to figure out another way of motivating free will illusionism or he needs to give up his claim that people really do have local compatibilist control. Until he takes one of these courses of action, we do not think the burden of motivating free will illusionism has been met.

While we are on the topic of argumentative burdens, it is worth pausing to consider precisely why it is Smilansky and not his opponents who must ultimately do the heavy lifting when it comes to establishing the empirical plausibility of free will illusionism. The first thing worth pointing out is that his view is selfreferentially puzzling. After all, Smilansky himself is presumably able to live a morally acceptable and personally gratifying life that is filled with meaningful choices and loving relationships. But if disillusionment did not have a deleterious effect on his own moral compass and sense of self-worth, why should we assume that everyone else would suffer in a way that he has seemingly not? Perhaps it is simply because Smilansky believes that the hoi polloi, unlike professional philosophers and psychologists, are not intellectually equipped to appreciate the small grain of truth contained in compatibilistically grounded notions of control and responsibility.

Indeed, this is precisely what he seems to have in mind when he says that 'reactions and practices which are at least partially valid (have compatibilist grounding) will not be sufficiently adhered to if the absence of libertarian free will is realized' (Smilansky, 2001, p. 87). As a result, Smilansky suggests that people may need 'mediated motivation and defense by illusion' (2002, p. 498). In short, he believes that there may be a need for a 'motivated obscurity' with respect to the objections to LFW and UMR (2002, p. 497). On this view, because the masses would likely throw out the compatibilist baby with the libertarian bathwater, those of us who are in the know should leave others to their illusory beliefs about free will and determinism.

Of course, this too is an empirical claim about people's general inability to appreciate the importance of compatibilist control and responsibility once they have internalized the cold truth about the non-existence of LFW and UMR. But that is another story for another day. For present purposes, we think it is sufficient to point out that until a concerted effort is made to further test the network of empirical assumptions Smilansky needs to motivate his view, we should refrain from adopting free will illusionism. For even if people do actually have illusory beliefs about things as central to their lives as LFW and UMR, we should only conspire to keep the truth hidden from them if we have good reason to suspect that the benefits of doing so outweigh the costs. As far as we are concerned, simply assuming tout court that the folk - unlike we philosophers and psychologists - are intellectually and emotionally ill-equipped to handle the truth is not a good enough

21 Given that epiphenomenalism may pose a real threat to our sense of control and autonomy, it is open for Smilansky to be an illusionist about epiphenomenalism even if being an illusionist about LFW and UMR turns out to be unnecessary. 
reason. That being said, it is now time to consider what Smilansky might say in light of our criticisms.

\section{Smilansky's Avenues of Response}

Perhaps the easiest way to canvass how Smilansky might respond is to divide our criticism into two parts. First, we used the data on perceived control to suggest that being disillusioned wouldn't undermine people's sense of local reflective control. Second, we used the data from developmental psychology to suggest that realizing that how one's life unfolds is largely a matter of luck doesn't have the deleterious effects one people's lives that Smilansky envisions. Let's call the former the Perceived Control Objection and the latter the Luck Objection. Since we believe the former is both more central and important to Smilansky's overall project than the latter, we will consider how he might respond to the latter objection first.

The thrust of the Luck Objection is that in at least one important respect, the kind of disillusionment that concerns Smilansky is something most of us already endure and survive as we age. After all, growing old appears to involve the eventual realization that how one's life unfolds is largely a matter of luck. As we saw earlier, the kind of up-to-usness that Smilansky suggests cannot be rectified with the ultimate perspective is something we eventually lose faith in just in virtue of retrospectively looking back on how the events of our lives played out. Yet, despite the fact that most of us come to believe in the end that in some important sense luck swallows everything, we nevertheless maintain our belief in both local reflective control and moral responsibility. And while it is clear that the elderly often have less perceived control, this has less to do with the increasing awareness of the role that luck plays in their lives than it does the actual diminution in objective control that is also part of the aging process. If this is true, then it is unclear that Smilansky's worries concerning the effect that disillusionment will purportedly have on our psychological well-being are empirically well-founded.

One way Smilansky could respond to the Luck Objection is by pointing out that there is a very important difference between the gradual awareness that luck swallows everything in the case of the elderly and the case of sudden disillusionment concerning LFW and UMR that he has in mind. On this view, the real problem is that the rate of disillusionment outstrips our ability to adjust to our new-found awareness that we lack LFW and UMR. ${ }^{22}$ Consequently, we may be tempted to succumb to knee jerk reactions about the moral status of ourselves and others. According to this line of response, it's not so much that the literature from developmental psychology is irrelevant per se, it's just that the time-scale involved is not of a piece with the process of disillusionment that Smilansky envisions.

22 We would like to thank Michael Bishop for bringing this potential line of reasoning to our attention. 
By our lights, while this is an attractive response to the Luck Objection, we are not sure it is a good move for Smilansky to make. First, it is unclear why we should assume that the process of disillusionment with respect to LFW and UMR need be a rapid rather than gradual one. Consider, for instance, the case of theists who slowly lose their faith. We see no reason to assume that the realization that we lack LFW and UMR has to come in a flash any more than we think we need to assume that religious conversion has to occur all at once. The process of ideological conversion - whether it be from theist to atheist, libertarian to hard determinist, meat eater to vegetarian, Democrat to Republican, etc. — can often be a slow and gradual process that involves our waffling between the old set of beliefs and practices and the new ones. As such, we are not sure that focusing on the relative speed of disillusionment concerning LFW and UMR, on the one hand, and the realization that from the ultimate perspective luck swallows everything, on the other hand, is a very promising avenue for Smilansky to pursue. That being said, it is nevertheless likely that disillusionment concerning LFW and UMR will occur more quickly for some than others. So, perhaps Smilansky could simply focus his attention on cases involving rapid disillusionment.

The first thing worth pointing out is that opting for this strategy of responding to the Luck Objection narrows the scope of Smilansky's views concerning disillusionment by limiting the applicability of illusionism to those who are likely to be disillusioned quickly rather than slowly. But setting that shortcoming aside, it is still unclear that Smilansky's worries are well-founded. To see why, consider once again the case of the individual who loses his faith in God, thereby making the transition from theism to agnosticism or atheism. Since religious beliefs are often intertwined with our beliefs concerning free will and moral responsibility, we believe the literature on the relationship between religiosity and well-being is relevant in the present context. And while it is a common-place assumption that religiosity is positively correlated with psychological well-being, the evidence is mixed. $^{23}$

Indeed, most of the available data suggest that atheists who come to terms with their atheism are just as psychologically stable and healthy as their religious counterparts. While the transition from theism to atheism can be painful in the short term, those who undergo this transition weather the storm with their sense of purpose intact (Ross, 1990). On our view, this provides prima facie evidence that people are more resilient that Smilansky seems to assume. Minimally, we see no reason for thinking that abandoning one's faith in LFW and UMR would be, in principle, more existentially problematic than losing one's faith in the existence of a personal God. And to the extent to which Smilansky must shoulder the responsibility for empirically motivating his view, we believe that the literature on atheism puts yet more pressure on his view. Of course, it is admittedly not

23 One can find data that suggest a positive correlation between mental health and religion as well as data that suggest a negative correlation. See, for instance, Hackney and Sanders, 2003; Lewis and Cruise, 2006; Schumaker, 1992; and Ventis, 1995. 
decisive. So, we now want to consider how else one might respond to the Luck Objection.

Another avenue available to Smilansky is simply to deny that the developmental literature is relevant to his views concerning disillusionment since the data we canvassed earlier concerning aging is completely compatible with the possibility that the kind of creeping luck under consideration could leave the elderly's beliefs in LFW and UMR intact. On this view, while we admittedly do come to gradually realize that the way our lives unfold is largely a matter of luck, this realization involves our broader circumstances and does not apply to our sense of volitional control. After all, we could consistently believe that we have LFW and UMR while nevertheless believing that the situations within which we exercise our volitional control are largely determined by factors entirely beyond our control. ${ }^{24}$ On this interpretation of the data on aging and luck, there is no evidence that our beliefs in LFW and UMR are curtailed in light of the gradual awareness that many factors of our lives that we previously thought were under our control are largely a matter of 'happenstance, luck, chance, fate, or coincidence' (Skinner, 1995, p. 118).

At first glance, this response to the Luck Objection appears to give Smilansky some empirical breathing room. Upon closer examination, however, it is unclear that this approach is as promising as it seems. For even if the developmental literature admittedly leaves open the possibility that the elderly continue to believe in LFW and UMR despite the fact that they slowly come to realize the role that luck played in the unfolding of their lives, it nevertheless shrinks the domain over which people think their volitional control matters. After all, one of the things that we come to realize as we age is that a number of things we used to take pride in having accomplished as the result of exercising our volitional will turn out in the end to be more contingent and accidental than we initially assumed. As we saw earlier, the developmental literature suggests that part of the aging process involves 'the realization of the limits of human control and the narrow range of outcomes that can potentially be influenced by human action' (Skinner, 1995, p. 122). And while it is certainly possible that LFW and UMR can be situated within this increasingly shrinking range of control, this would provide Smilansky with a pretty thin empirical foundation upon which to build his view. Minimally, the developmental literature suggests that there are a sizeable number of things we eventually realize are not up to us and yet we nevertheless manage to keep sight of the fact that we often have the ability to exercise volitional control over our immediate actions.

For present purposes, however, we want to set the Luck Objection aside since we feel it is a less penetrating objection to Smilansky's view than the Perceived Control Objection. So, we now want to consider how he might respond to our use of the literature on perceived control. By our lights, the most obvious way for Smilansky to respond involves simply denying that we have sketched an accurate

24 We would like to thank an anonymous referee for bringing this possibility to our attention. 
account of his views concerning illusionism. According to this line of reasoning, his view is not that if people become disillusioned about LFW and UMR they will cease to believe that they have the compatibilist control they do in fact have. Rather, his view is that even if people do continue to believe that they have local reflective control, they will nevertheless lose sight of the fact that this is enough to ground the all-important community of responsibility which Smilansky believes is crucial for both interpersonal and intrapersonal well-being. ${ }^{25}$

On this interpretation of illusionism, the issue is not that viewing ourselves from the ultimate perspective will curtail our belief that we have local reflective control; it is that we will mistakenly conclude that this more shallow kind of control is not enough to ground our notions of moral responsibility. If this is correct, then the characterization of Smilansky's view that we put forward earlier fails to capture his view. After all, we cashed out the second premise of his view in the following way:

2. If people were disillusioned about LFW and UMR, then they would lose sight of the fact that there is an important grain of truth in compatibilism-namely, that human beings do have the kind of local control that is necessary for grounding most of our moral practices as well as our sense of well-being.

If Smilansky's concern is primarily focused on our sense of moral responsibility and not our sense of control, then this second premise needs to be recast. The amended premise would have the following form:

2.* If people were disillusioned about LFW and UMR, then they would lose sight of the fact that the kind of local control that humans actually have is sufficient for grounding our moral practices as well as our sense of well-being.

This interpretation of illusionism would enable Smilansky to sidestep our attempt to use the literature on perceived control to put pressure on his view. After all, on this account the issue is not whether people's belief in compatibilist control will weather the storm of hard determinism but whether our moral practices will survive intact.

While it is unclear to us that Smilansky is solely concerned with our moral sensibilities rather than control-especially given that the latter issue is presumably what drives the intrapersonal crisis that would purportedly be caused by disillusionment-it is clear that he is no less worried about the former than the latter. After all, if people could maintain their belief in both compatibilist control and moral responsibility in the face of the ultimate perspective, there would be no role whatsoever for illusion to play. According to this line of response to the Perceived Control Objection, the problem is that even if our belief in compatibilist control

25 We would like to thank the anonymous referee for pointing out that we need to address this response. 
doesn't wither in the face of hard determinism, the community of responsibility may not be so lucky. That being said, it appears that we need to make an additional distinction concerning Smilansky's worries about the moral domain. On the one hand, he suggests that we will cease to believe in desert and justice if we become disillusioned about LFW and UMR. On the other hand, he suggests that we will cease to hold ourselves morally accountable for our actions. We are going to call the former the Interpersonal Worry and the latter the Intrapersonal Worry. The question we now want to consider is whether these respective worries are themselves empirically well-founded.

For starters, it is worth pointing out that we are happy to concede that the Interpersonal Worry is one of the main issues driving Smilansky's flight to illusion. But before we examine some psychological studies that suggest this worry is somewhat misplaced, we want to first trace the contours of Smilansky's concern in a bit more detail. Consider, for instance, the following remarks:

The ethical importance of the paradigm of free will and responsibility as a basis for desert should be taken very seriously. But the ultimate perspective threatens to present it as a farce, a mere game without a foundation ... The idea of action-based desert [and] true internal acceptance of responsibility ... are threatened by the leveling or homogenizing view arising from the ultimate perspective (Smilansky, 2002, p. 501).

On this view, there are important moral distinctions that need to be drawn along compatibilist lines-e.g. the difference between the kleptomaniac and the common thief-even in a determined world since these distinctions are crucial to our moral form of life (Smilansky, 2002, p. 493). Hence, even if the ultimate perspective reveals that nothing is up to us in some cosmic sense, there is a kind of compatibilist control that provides us with the grounds for distinguishing those who deserve punishment from those who don't. The primary example Smilansky relies on in trying to convey what he has in mind is the Case of the Lazy Waiter:

Take the example of a waiter working at a café. He is young and healthy, his pay is reasonable, the hours not too long. There is also a shortage of waiters so he may feel reasonably certain that he can keep the job as long as he wishes. In short, our waiter has an agreeable job. Part of his earnings depend on tips, and let us assume that the level of tips is directly related to how he serves his customers. This waiter, however, usually does the minimum, is slow and inattentive to the customers, and makes little effort to be helpful or pleasant. There is nothing extreme in his behavior or in the motivation behind it, and he is quite capable of behaving differently, for example when his relatives come to the café or when a customer known to be particularly generous appears. But normally he is prepared to make no more than the very minimal effort required (2002, p. 493). 
According to Smilansky, the lazy waiter does not deserve a full tip regardless of whether he has LFW and UMR since in this case the waiter has (a) local reflective control and (b) the ability to do otherwise. On this view, so long as an individual satisfies these two conditions, she can legitimately be blamed and punished for her actions. Smilansky's Interpersonal Worry is driven by the assumption that if people lose faith in LFW and UMR, they will either blur the distinction between the truly innocent and the truly guilty or they will succumb to 'pragmatic consequentialist temptations' when it comes to meting out punishment. After all, if everyone is mistakenly placed on the same moral plane with respect to blame and desert, the only grounds left for punishment are forwardlooking rather than the kinds of deontological considerations that Smilansky suggests are necessary if we are to show a proper respect for people's autonomy (2002, p. 501).

We are now going to argue that there is gathering evidence that Smilansky may very well have gotten things backwards. Rather than dampening retributivism and muting beliefs concerning moral desert and justice, it appears that determinism may actually intensify both. The converse appears to be true as well-i.e. people who believe that humans have the self-creating ability to change their desires, beliefs, and actions are actually less punitive and more interested in rehabilitation. But we are getting ahead of ourselves. In order to put empirical pressure on Smilansky's Interpersonal Worry, we are going to focus on two different research programs in social psychology. The first is associated with the work of Wayne Viney and the second is associated with the work of Carol Dweck - which we are now going to examine in turn.

In the early 1980s, Viney and his colleagues set out to explore the relationship between people's beliefs about free will and determinism and their ascriptions of blame and punishment. One of the motivating assumptions of this research was that 'the philosophical justifications for punishment are assumed to be different for determinists than for those who believe in free will ... presumably, determinists, to the extent that they justify punishment at all, are likely to support a utilitarian approach' (Viney et al., 1988, p. 15). This is a difference that Viney expected to find in participants' responses to questions concerning blame and punishment. For instance, in Viney et al. (1982), we find the following prediction:

The hypothesis was that libertarians ... will consistently recommend more punitive measures for behavioral deviations than determinists ... It could be argued that determinists are more likely to explain behavioral deviation in terms of genetic or environmental circumstances which have shaped behavior in unfortunate directions. The libertarian, on the other hand, might be apt to view the person as the source of undesirable behavior. Presumably, blame and retribution would be more consistent with the libertarian position while reformation and therapy would be more consistent with the determinist's position (1982, p. 940). 
However, much to Viney's surprise, the results of his early studies did not support this hypothesis. Indeed, the studies suggest that libertarians are actually less punitive than determinists! So, rather than providing empirical support for the orthodox philosophical position concerning the relationship between free will, determinism, blame, and punishment - whereby hard determinists are less punitive than their libertarian counterparts - the early studies run by Viney et al. found 'a significant negative correlation between total FWD scores and total punishment scores [that] supports an opposite conclusion: namely, that determinists recommend more punitive measures for behavioral deviations than libertarians' (Viney et al., 1982, p. 943).

Following up on his earlier work, Viney later set out to further explore folk judgments concerning free will, moral responsibility, and punishment (Viney et al., 1988). This time, he first gave participants the Free Will-Determinism Scale that had been used in the aforementioned 1982 studies. $^{26}$ They were then presented with brief accounts of the following four common felonies:

1. Felony 1: premeditated murder;

2. Felony 2: carefully planned burglary;

3. Felony 3: arson;

4. Felony 4: manslaughter.

Next, participants were asked to not only make recommended punishments for each offense, but were also asked to state their rationale for the punishment they chose for each offense. The four possible rationales were (a) to rehabilitate or reform the defendant, (b) to protect society, (c) to give the defendant the punishment she deserves, and (d) to inflict pain or make the defendant pay for the crime. Given this experimental design, the higher a participant's score, the more retributive the punishment is taken to be. The results of this study - which did not entirely settle with the earlier data-were as follows:

1. A significant relationship was found between rationale for punishment and the type of felony.

2. Correlational analysis failed to uncover any reliable relationships between performance on the FWD scale and the magnitude of the recommended punishments.

3. Correlational analysis failed to uncover any reliable relationships between performance on the FWD scale and rationales for punishment.

In light of these results, Viney et al. conclude that 'the present studies found neither reliable correlations between punitiveness and beliefs in free will or determinism nor reliable correlations between rationales for punishment and beliefs in free will or determinism' (Viney et al., 1988, p. 20). So, while this study failed to show a positive correlation between determinism and punitiveness, it nevertheless

26 The FWD was subjected to a validity study in Viney et al., 1984. 
provides further evidence that the standard philosophical orthodoxy concerning free will, determinism, desert, and punishment may not adequately capture folk intuitions.

That we should reconsider our traditional assumptions concerning folk intuitions and judgments concerning these issues is further supported by closely related work done by Steven Stroessner and Charles Green (1990), who began by distinguishing between the following: (a) psychosocial determinism-i.e. 'the belief that environmental factors determine our behavior', (b) religious-philosophical determinism-i.e. 'the belief that a force such as God or fate acts to control our behavior', and (c) libertarianism-i.e. 'the belief in free will' (1990, p. 791). With this distinction in hand, Stroessner and Green went on to predict that, (a) psychological determinists would be more rehabilitative and less punitive, (b) religious-philosophical determinists would be both rehabilitative and punitive, and (c) libertarians would be punitive but not rehabilitative.

As was the case with the aforementioned Viney studies, things did not turn out as expected. Indeed, Stroessner and Green were surprised to find that the punitive scores of the extreme psychosocial determinists 'were as high as those of libertarians and religious-philosophical determinists' (1990, p. 797). Moreover, this difference couldn't be explained in forward-looking rehabilitative terms given that 'extreme psychosocial determinists were more punitive than others even on the two items on the punitive scale dealing with the death penalty' (1990, p. 797). By our lights, their comparative data on the moral intuitions of those who believe that humans have robust free will and those who believe that human behavior is largely determined is telling. Minimally, we believe that when we consider Smilansky's view in light of the results of the work done by Viney, Stroessner, Green, and others, it is unclear that the Interpersonal Worry is well-founded. After all, it appears that people who have deterministic leanings are no less punitive than those who believe in free will. This is a finding that is further supported by the work of Dweck and her colleagues on what is called Implicit Person Theory (IPT). As we are about to see, this body of literature gives us yet more reason to suspect that the after-shock of disillusionment concerning LFW and UMR will be more muted than Smilansky has assumed.

For the past ten years, there has been an active research program that examines the role that implicit theories play at both the interpersonal and intrapersonal levels. In this essay, we are going to follow Gervey et al. (1999) in defining an implicit theory as 'a framework for processing information, constructing representations of social events, and making inferences' (1999, p. 17). These domain-general implicit theories about the relative malleability of personal attributes not only 'contribute to the variability, coherence, and uniqueness of personal functioning of society, but they also shape how people interpret events, reflect on themselves, and plan courses of action' (Cervone, 2004, p. 183). Research into IPT has revealed that people generally fall into two fairly distinct camps when it comes to the underlying moral theories they rely on in making moral inferences from limited information: 
An entity person theory refers to the belief that personal characteristics are fixed entities despite a person's efforts or motivation to change them: that is, they are not under personal control ... In contrast, an incremental person theory refers to the belief that personal characteristics are malleable and can be developed with time and effort (Levy et al., 2001, p. 157).

According to Dweck and Molden (2008), people's self theories lead to different beliefs, experiences, and judgments concerning free will. Moreover, it appears that 'perceptions of free will within the different self-theories ... mirror those of different philosophical traditions' (Dweck and Molden, 2008, p. 44). Consider, for instance, the following characterizations of the distinction between entity theorists and incremental theorists as it pertains to the free will debate:

\section{Entity Theory:}

In the world of entity theorists, free will appears to be either absent or difficult and rare. This is because entity theorists believe (a) that human character and personality are fixed, (b) tend to view this fixed character or personality as the primary cause of action, and (c) do not tend to emphasize controllable motivational processes in the chain of influence. Thus, entity theorists may have much in common with free will skeptics (Dweck and Molden, 2008, p. 53).

\section{Incremental Theory:}

Incremental theorists and these philosophers [i.e. libertarians] share the belief in the power of human beings to perform self-forming actions, emphasize the chain of psychological-motivational events (beliefs, desires, intentions) that influence behavior, and subscribe to the probabilistic nature of the causal factors that produce behavior (Dweck and Molden, 2008, p. 53).

Given that entity theorists believe in fixed character traits that are largely beyond our control, one would expect that they would be less punitive than their incremental counterparts. However, once again we find that things are markedly less obvious than philosophers and psychologists have traditionally assumed. Indeed, it turns out that entity theorists were 'significantly more likely to consider punishment or retribution as the primary function of imprisonment than were incremental theorists, who were in turn were more likely than entity theorists to consider rehabilitation as the primary function of imprisonment' (Gervey et al., 1999, p. 22). More importantly for present purposes, it appears that 'those people who are more committed to determinism (via the belief that human character is fixed and deterministic) are also more likely to believe in strict and direct punishment in the form of retributive justice (and eye for an eye)' (Dweck and Molden, 2008, p. 45).

Contrary to Smilansky's assumptions concerning the relationship between determinism and blame attribution, the gathering data suggest that even if people's traits are taken to be caused by internal mental states that agents are powerless to change, they can still be condemned for these behaviors. To get a feel for how these 
differences play out in practice, consider, for instance, the results of the following study:

After watching a slide show about a series of transgressions committed by a new boy in school, students who held an entity theory (a) showed greater moral condemnation of the boy and (b) recommended significantly more severe punishment than did incremental theorists (see Chiu et al., 1997, and Loeb and Dweck, 1994, for similar results with college students). Interestingly, entity and incremental theorists tend to rate a given transgression as equally wrong, serious, or negative, so it is not the case that incremental theorists simply have more lenient standards. It is when entity and incremental theorists come to judge the moral character of the transgressors and the punishment they deserve that they part ways (Dweck and Molden, 2008, pp. 51-2).

In stark contrast both to Smilansky's Interpersonal Worry and to the philosophical orthodoxy concerning folk intuitions about the relationship between blame attribution and determinism, there is a large body of evidence that suggests that entity theorists (i.e. naive determinists) view retribution as the highest priority in responding to moral transgressions. Incremental theorists (i.e. naive libertarians), on the other hand, believe that education, rehabilitation, and reform are the main goal of punishment (Dweck and Molden, 2008, p. 52). In short, not only do people's respective implicit theories concerning free will and determinism affect their intuitions concerning the proper severity, type, and justification of punishment, but they do so in a way that runs counter to what philosophers-including Smilansky - have traditionally assumed. Hence, if Smilansky wants to motivate free will illusionism by trading on the supposed fact that disillusionment about LFW will erode the community of responsibility by undermining the notion of desert that undergirds it, relying on anecdotal evidence or philosophical orthodoxy simply won't do - not when there is a large body of evidence that suggests we have less to worry about in this regard than we have been led to believe.

That being said, we now want to turn our attention to the other concern raised by Smilansky -i.e. what we are calling the Intrapersonal Worry. As we saw earlier, Smilansky's DDA can be cashed out in two distinct ways. On the one hand, he seems to be worried about the effect disillusionment will have on the moral attitudes we adopt towards others. On the other hand, he seems to be worried about the effect it will have on the moral attitudes we adopt towards ourselves. Having already addressed the former worry, we now want to focus on the latter. The first thing worth pointing out when it comes to the Intrapersonal Worry is that the results of some recent psychological studies appear to show that Smilansky is on firmer empirical footing when it comes to this particular concern.

Kathleen Vohs and Jonathan Schooler, for instance, have recently reported the results of some studies that purportedly show that when participants are induced to both believe in determinism and disbelieve in free will, they are more likely to engage in immoral behavior such as cheating (2008). Indeed, the conclusion they 
draw - namely, that 'the fact that brief exposure to a message asserting that there is no such thing as free will can increase both passive and active cheating raises the concern that advocating a deterministic worldview could undermine moral behavior' (Vohs and Schooler, 2008, p. 53) — is strikingly similar to Smilansky's own concern. They even suggest at one point that 'it is possible that free will is an illusion that nevertheless offers some functionality' (Vohs and Schooler, 2008, p. 53). As such, their studies seem to provide Smilansky with some ammunition with which to argue for illusionism. However, we are unconvinced that the results of the Vohs and Schooler studies show what they think they show-but that need not concern us here. By our lights, criticizing their experimental design and background assumptions is a story for another day. For even if the Vohs and Schooler studies were unproblematic and their interpretations of the data were correct, we don't think it would help Smilansky. As such, our present task is simply to explain the source of our skepticism on this latter front.

Vohs and Schooler begin with the following question: 'What would happen if people came to believe that their behavior is the inexorable product of a causal chain set into motion without their own volition?' (Vohs and Schooler, 2008, p. 49). The way this question is framed makes it clear that Vohs and Schooler have conflated determinism-i.e. the view that there is only one possible future given the past and the laws of nature - with epiphenomenalism - i.e. the view that our conscious wills are causally inert. Given that one of the main issues in the free will debate is whether determinism is compatible with the causal efficacy of our conscious will, the fact that Vohs and Schooler begin their investigation by lumping determinism and epiphenomenalism together is highly problematic. For while it is certainly possible that both determinism and epiphenomenalism are true, the latter is not entailed by the former-which, as we saw earlier, is something Smilansky himself is quick to point out. Hence, insofar as the results of the Vohs and Schooler studies are partly driven by the conflation of determinism and epiphenomenalism, these results cannot provide Smilansky with the help he needs. After all, on his view, determinism does not preclude the causal efficacy of our locally reflective conscious will. Indeed, his primary concern is that people won't appreciate that the kind of local compatibilist control we do have is enough to ground moral responsibility. Consequently, evidence that people behave less morally if they are led to believe that their conscious will is causally inert-i.e. that they do not have local reflective control-is not germane to Smilansky's project however interesting the data might be otherwise.

So, even if Vohs and Schooler are correct that 'advocating a deterministic worldview that dismisses individual causation' may lead to undesirable behavior (2008, p. 50) - and we are not convinced they are - this is not the kind of data Smilansky needs to motivate his Intrapersonal Worry. In order to empirically ground his concern, he needs evidence that people who are disillusioned about LFW and UMR will cease to believe that their local reflective control is sufficient to ground the community of responsibility. As such, showing that people who are led to believe that human behavior is under the control of predetermined forces are 
more likely to engage in immoral behavior than people who are not led to believe that behavior is predetermined lends no support to the Intrapersonal Worry. Once again, it appears that Smilansky's concerns - as intuitive as they may be - are not well-supported by the existing empirical data. Hence, if he wants us to follow him down the road to free will illusionism, there is a lot of empirical spadework that remains to be done.

\section{Conclusion}

Saul Smilansky's free will illusionism is as timely as it is novel. Given the recent interest by scientists and the popular press in the relationship between developments in psychology and the traditional free will debate, philosophers certainly need to add our voice to the chorus of interest. For if one thing is clear, it's that psychologists and pundits need our help in sketching the contours of human agency and moral responsibility in the face of scientific progress. Along these lines, Smilansky has done an admirable job of raising important red flags and fleshing out some of the difficulties that may lie ahead. But for all that, his view-based as it is on hiding what he takes to be the truth about free will and responsibility from the masses - ought to give us pause for concern. Minimally, a number of assumptions concerning folk intuitions and moral practices would need to hold true if free will illusionism is to merit our allegiance. In this paper, we have considered several of the empirical claims Smilansky needs to support his view. In light of data from both developmental and social psychology, we have tried to show that he has yet to establish that the specific worries that undergird free will illusionism are well-supported. Of course, if it turns out that future studies show that Smilansky's empirical assumptions are correct after all, then we will be forced to reconsider his view anew. Until then, we believe we have provided adequate evidence that we ought to refrain from being illusionists about free will and moral responsibility.

Department of Philosophy

Dickinson College

\section{References}

Abramson, L. and Alloy, L. 1981: Depression, non-depression, and cognitive illusions: a reply to Schwartz. Journal of Experimental Psychology: General, 110, 436-47.

Abramson, L., Metalsky, G. and Alloy, L. 1989: Hopelessness depression: a theory-based subtype of depression. Psychological Review, 96, 358-72.

Ackermann, R. and DeRubeis, R. J. 1991: Is depressive realism real? Clinical Psychology Review, 11, 565-84. 
Alloy, L. and Abramson, L. 1979: Judgment of contingency in depressed and nondepressed students: sadder but wiser? Journal of Experimental Psychology: General, 108, $441-85$.

Allport, G. 1943: Becoming: Basic Considerations for a Psychology of Personality. New Haven, CT: Yale University Press.

Averill, J. 1973: Personal control over aversive stimuli and its relationship to stress. Psychological Bulletin, 80, 286-303.

Ayer, A. J. 1954: Philosophical Essays. London: Macmillan.

Bandura, A. 1977: Social Learning Theory. Englewood Cliffs, NJ: Prentice-Hall.

Bargh, J. and Tota, M. 1988: Context-dependent automatic processing in depression: accessibility of negative constructs with regard to self but not others. Journal of Personality and Social Psychology, 54, 925-39.

Beck, A. 1967: Depression: Clinical, Experimental, and Theoretical Aspects. New York: Harper and Row.

Beck, A. 1976: Cognitive Therapy and the Emotional Disorders. New York: International University Press.

Brown, J. 1986: Evaluations of self and others: self-enhancement biases in social judgment. Cognition, 4, 353-76.

Burger, J. 1989: Negative reactions to increases in perceived personal control. Journal of Personality and Social Psychology, 56, 246-56.

Campbell, J. and Fairey, P. 1985: Effects of self-esteem, hypothetical explanations, and verbalization of expectancies on future performance. Journal of Personality and Social Psychology, 48, 1097-1111.

Cervone, D. 2004: The architecture of personality. Psychological Review, 111, 183-204.

Chiu, C., Dweck, C., Tong, J. and Fu, J. 1997: Implicit theories and conceptions of morality. Journal of Personality and Social Psychology, 73, 923-40.

Colvin, C. and Block, J. 1994: Do positive illusions foster mental health? An examination of the Taylor and Brown formulation. Psychological Bulletin, 116, $3-20$.

Cummins, R. and Nistico, H. 2002: Maintaining life satisfaction: the role of positive cognitive bias. Journal of Happiness Studies, 3, 37-69.

DeCharms, R. 1968: Personal Causation. New York: Academic Press.

DeCharms, R. 1981: Personal causation and locus of control: two different traditions and two uncorrelated constructs. In H. M. Lefcourt (ed.), Research with the Locus of Control Construct: Vol. 1. San Diego, CA: Academic Press, 337-58.

Deci, E. 1975: Intrinsic Motivation. New York: Plenum.

Deci, E. and Ryan, R. M. 1985: Intrinsic Motivation and Self-Determination in Human Behavior. New York: Plenum. 
Dweck, C. and Molden, D. 2008: Self-theories: the construction of free will. In J. Baer, J. Kaufman, and R. Baumeister (eds), Are We Free? Psychology and Free Will. Oxford University Press, 44-64.

Fiske, S. and Taylor S. 1984: Social Cognition. Reading: Addison-Wesley.

Gervey, B., Chiu, C., Hong, Y. and Dweck, C. 1999: Differential use of person information in decisions about guilt versus innocence: the role of implicit theories. Personality and Social Psychology Bulletin, 25, 17-27.

Golin, S., Terrell, T. and Johnson, B. 1977: Depression and the illusion of control. Journal of Abnormal Psychology, 86, 440-42.

Greenberg, M., Vazquez, C. and Alloy, L. 1988: Depression versus anxiety: differences in self and other schemata. In L. Alloy (ed.), Cognitive Processes in Depression. New York: Guilford Press, 109-42.

Greenwald, A. 1980: The totalitarian ego: fabrication and revision in personal history. American Psychologist, 35, 603-18.

Hackney, C. and Sanders, G. 2003: Religiosity and mental health: a meta-analysis of recent studies. Journal for the Scientific Study of Religion, 42, 43-55.

Haidt, J. and Rodin, J. 1999: Control and efficacy in interdisciplinary bridges. Review of General Psychology, 3, 317-77.

Harter, S. 1978: Effectance motivation reconsidered: toward a developmental model. Human Development, 1, 661-69.

Heider, F. 1958: The Psychology of Interpersonal Relations. New York: Wiley.

Horswill, M. and McKenna, F. 1999: The effect of perceived control on risk taking. Journal of Applied Social Psychology, 29, 377-91.

Jahoda, M. 1958: Current Concepts of Positive Mental Health. New York: Basic Books.

Jourard, S. and Landsman, T. 1980: Healthy Personality: An Approach from the Viewpoint of Humanistic Psychology, $4^{\text {th }}$ edn. New York: Macmillan.

Kuiper, N. 1978: Depression and causal attributions for success and failure. Journal of Personality and Social Psychology, 36, 236-46.

Kuiper, N. A. and Derry, P. A. 1982: Depressed and non-depressed content selfreference in mild depression. Journal of Personality, 50, 67-79.

Langer, E. 1975: The illusion of control. Journal of Personality and Social Psychology, 32, 311-28.

Langer, E. and Roth, J. 1975: Heads I win, tails it's chance: the illusion of control as a function of the sequence of outcomes in a purely chance task. Journal of Personality and Social Psychology, 32, 951-55.

Levy, S., Plaks, J., Hong, Y., Chiu, C. and Dweck, C. 2001: Static versus dynamic theories and the perception of groups: Different routes to different destinations. Personality and Social Psychological Review, 5, 156-68. 
Lewinsohn, P., Mischel, W., Chaplin, W. and Barton, R. 1980: Social competence and depression: the role of illusory self-perceptions. Journal of Abnormal Psychology, 89, 203-12.

Lewis, C. and Cruise, S. 2006: Religion and happiness: consensus, contradictions, comments and concerns. Mental Health, Religion and Culture, 9, 213-25.

Loeb, I. and Dweck, C. 1994: Beliefs about human nature as predictors of reactions to victimization. Paper presented at the conference of the American Psychological Society, Washington, DC.

Miller, D. and Ross, M. 1975: Self-serving biases in attribution of causality: fact or fiction? Psychological Bulletin, 82, 213-25.

Mischel, W. 1973: Toward a cognitive-social learning reconceptualization of personality. Psychological Review, 80, 252-83.

Nadelhoffer, T. and Feltz, A. 2007: Folk intuitions, slippery slopes, and necessary fictions: An essay on Smilansky's free will illusionism. Midwest Studies in Philosophy, 13, 202-13.

Nahmias, E. 2006: Folk fears about freedom and responsibility: determinism vs. reductionism. Journal of Cognition and Culture, 6, 215-37.

Nahmias, E., Morris, S., Nadelhoffer, T. and Turner, J. 2005: Surveying free will: folk intuitions about free will and moral responsibility. Philosophical Psychology, 18, 561-84.

Nahmias, E., Morris, S., Nadelhoffer, T. and Turner, J. 2006: Is incompatibilism intuitive? Philosophy and Phenomenological Research, 73, 28-53.

Nisbett, R. and Ross, L. 1980: Human Inference: Strategies and Shortcomings of Social Judgment. Englewood Cliffs, NJ: Prentice-Hall.

Ross, C. 1990: Religion and psychological distress. Journal for the Scientific Study of Religion, 29, 236-45.

Schumaker, J. 1992: Mental health consequences of irreligion. In J. Schumaker (ed.), Religion and Mental Health. New York: Oxford University Press, 54-69.

Skinner, E. 1995: Perceived Control, Motivation, and Coping (Individual Differences and Development). Thousand Oaks, CA: Sage Publications.

Skinner, E. 1996: A guide to constructs of control. Journal of Personality and Social Psychology, 71, 549-70.

Smilansky, S. 2000: Free Will and Illusion. New York: Oxford University Press.

Smilansky, S. 2001: Free will: from nature to illusion. Proceedings of The Aristotelian Society, 101, 71-95.

Smilansky, S. 2002: Free will, fundamental dualism, and the centrality of illusion. In R. Kane (ed.), The Oxford Handbook of Free Will. Oxford: Oxford University Press, 489-505.

Spacapan, S. and Thompson, S. 1991: Perceived control in vulnerable populations. Journal of Social Issues, 47, 1-21. 
Stace, W. 1953: Religion and the Modern Mind. London: Macmillan.

Strawson, G. 1998: Luck swallows everything. Times Literary Supplement, 26 June, 8-10.

Stroessner, S. and Green, C. 1990: Effects of belief in free will or determinism on attitudes toward punishment and locus of control. The Journal of Social Psychology, 130, 789-99.

Taylor, S. 1989: Positive Illusions: Self Deception and the Healthy Mind. New York: Basic Books.

Taylor, S. and Brown, J. 1988: Illusion and well-being: a social psychological perspective of mental health. Psychological Bulletin, 103, 193-210.

Vaillant, G. 1977: Adaptation to Life. Boston: Little, Brown.

Ventis, W. 1995: The relationships between religion and mental health. Journal of Social Issues, 51, 33-48.

Viney, W., McIntyre, R. and Viney, D. 1984: Validity of a scale designed to measure beliefs in free will and determinism. Psychological Reports, 54, 867-72.

Viney, W., Parker-Martin, P. and Dotten, S. 1988: Beliefs in free will and determinism and lack of relation to punishment rationale and magnitude. Journal of General Psychology, 115, 15-23.

Viney, W., Waldman, D. and Barchilon, J. 1982: Attitudes towards punishment in relation to beliefs in free will and determinism. Human Relations, 35, 939-50.

Vohs, K. and Schooler, J. 2008: The value of believing in free will: encouraging a belief in determinism increases cheating. Psychological Science, 19, 49-54.

White, R. 1959: Motivation reconsidered: the concept of competence. Psychological Review, 66, 297-335. 